\title{
CLINICAL OBSERVATIONS IN NEWBORN PREMATURE INFANTS
}

\author{
BY \\ RUTH L. CORT \\ From the Institute for the Care of Mother and Child, Prague, Czechoslovakia
}

(RECEIVED FOR PUBLICATION MAY 30, 1961)

Prematurity is one of the leading causes of death in the neonatal period. Most deaths in premature infants occur during the first two to three days of life (Holmdahl, 1952).

This study was undertaken in an attempt to correlate clinical impressions as to the vitality and prognosis of infants admitted to a premature department with additional clinical data during the first four days of life. We were particularly interested in regurgitation which often hinders early establishment of satisfactory nutrition and is the chief reason for starvation of newborn premature infants (Smith, 1957). Some observations of physiological interest were also made, chiefly with respect to body temperature and weight loss.

\section{Material and Methods}

Every infant born in our hospital and admitted to the premature department between January 1958 and October 1959 was included in the group for study, a total of 155 .

Since infants of diabetic mothers are routinely admitted to another ward, the proportion of such infants in this material was unusually small.

During the first four days of life the nurses made notes, on specially prepared forms, of body temperature, weight, frequency and intensity of regurgitation, stools, feeds, and 'appetite'. Since the nursing staff on this ward is stable and experienced, the observations were considered reliable. These notes were supplemented by data from daily doctors' notes and maternal records. No substantial change in clinical regimen took place during the period of study.

The data from each infant were assembled on individual cards. Data relating to feeds, etc., were recorded in accurately divided 24-hour periods, and weight loss was calculated per 24 hours from inspection of weight curves. Using these data cards, punch cards were prepared for each infant to facilitate classification and summary of the findings.

The data were subjected, where appropriate, to statistical analysis by use of the $t$-test for difference of means and correlation coefficients where possible (Fisher, 1948).

\section{Results}

The composition of the group is shown in Table 1. Because of incompleteness of data, 31 of the 155 infants were rejected from the study of clinical behaviour. The group as a whole, divided according to birth weight and gestational age with mortality in each weight and age group, is shown in Table 2.

Mortality. In confirmation of general experience (Holmdahl, 1952), the highest proportion of deaths

TABLE 1

NUMBER OF INFANTS IN STUDY

\begin{tabular}{cc|c|c|c}
\hline Study & & Survived & Died & Total \\
\hline Complete &. & 106 & 18 & 124 \\
Incomplete &. & 20 & 11 & 31 \\
\hline Total &. & 126 & 29 & 155 \\
\hline
\end{tabular}

Mortality $18 \cdot 7 \%$

TABLE 2

MORTALITY BY BIRTH WEIGHT AND GESTATIONAL AGE

\begin{tabular}{|c|c|c|c|c|}
\hline & Survived & Died & Total & $\begin{array}{c}\% \\
\text { Mortality }\end{array}$ \\
\hline 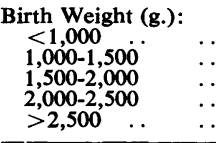 & $\begin{array}{r}0 \\
4 \\
45 \\
71 \\
6\end{array}$ & $\begin{array}{r}5 \\
11 \\
9 \\
4 \\
0\end{array}$ & $\begin{array}{r}5 \\
15 \\
54 \\
75 \\
6\end{array}$ & $\begin{array}{c}100 \\
73 \\
16 \cdot 7 \\
5 \cdot 3 \\
0\end{array}$ \\
\hline Total & 126 & 29 & 155 & \\
\hline 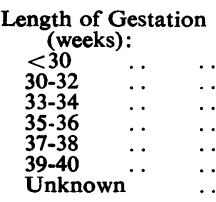 & $\begin{array}{r}3 \\
14 \\
22 \\
53 \\
18 \\
12 \\
4\end{array}$ & $\begin{array}{l}9 \\
9 \\
5 \\
3 \\
1 \\
1 \\
1\end{array}$ & $\begin{array}{r}12 \\
23 \\
27 \\
56 \\
19 \\
13 \\
5\end{array}$ & $\begin{array}{r}75 \\
39 \\
18.5 \\
5.4 \\
5.3 \\
7 \cdot 7 \\
20 \cdot 0\end{array}$ \\
\hline Total & 126 & 29 & 155 & \\
\hline
\end{tabular}


TABLE 3

NEONATAL MORBIDITY AND MORTALITY

\begin{tabular}{|c|c|c|c|c|c|c|c|c|}
\hline \multirow{2}{*}{$\begin{array}{l}\text { Birth } \\
\text { Weight } \\
\text { (g.) }\end{array}$} & \multirow{2}{*}{$\begin{array}{c}\text { Gestational } \\
\text { Age } \\
\text { (weeks) }\end{array}$} & \multirow[b]{2}{*}{ Number } & \multicolumn{6}{|c|}{ Per cent. Incidence of } \\
\hline & & & $\begin{array}{l}\text { Poor } \\
\text { Obstetric } \\
\text { History* }\end{array}$ & $\underset{\text { Birth } \dagger}{\text { Abnormal }}$ & $\begin{array}{c}\text { Delayed } \\
\text { Onset of } \\
\text { Respiration }\end{array}$ & Oedema & Morbidity & Mortality \\
\hline$<1,000$ & $<30$ & 5 & & & & & & 100 \\
\hline $1,000-1,500$ & $\begin{array}{l}\geqq 30 \\
\quad 31-34 \\
>34\end{array}$ & $\begin{array}{l}9 \\
6 \\
1\end{array}$ & $\begin{array}{l}100 \\
100\end{array}$ & $\begin{array}{r}100 \\
66\end{array}$ & $\begin{array}{r}100 \\
33\end{array}$ & $\begin{array}{r}100 \\
67\end{array}$ & $\begin{array}{r}100 \\
33\end{array}$ & $\begin{array}{r}89 \\
50 \\
100\end{array}$ \\
\hline $1,500-2,000$ & $\begin{aligned} & 30-34 \\
& 35-36 \\
\geqq & 37\end{aligned}$ & $\begin{array}{r}25 \\
20 \\
7\end{array}$ & $\begin{array}{l}65 \\
61 \\
29\end{array}$ & $\begin{array}{l}40 \\
44 \\
29\end{array}$ & $\begin{array}{r}40 \\
28 \\
0\end{array}$ & $\begin{array}{r}55 \\
22 \\
0\end{array}$ & $\begin{array}{r}60 \\
50 \\
0\end{array}$ & $\begin{array}{l}20 \\
10 \\
12\end{array}$ \\
\hline $2,000-2,500$ & $\begin{aligned} & 30-34 \\
& 35-36 \\
\geqq & 37\end{aligned}$ & $\begin{array}{l}18 \\
28 \\
31\end{array}$ & $\begin{array}{l}53 \\
50 \\
58\end{array}$ & $\begin{array}{l}13 \\
32 \\
29\end{array}$ & $\begin{array}{l}20 \\
14 \\
10\end{array}$ & $\begin{array}{l}20 \\
29 \\
10\end{array}$ & $\begin{array}{l}33 \\
18 \\
10\end{array}$ & $\begin{array}{r}16 \\
0 \\
3\end{array}$ \\
\hline$>2,500$ & $?$ & 4 & 50 & 75 & 75 & 50 & 50 & 0 \\
\hline
\end{tabular}

All percentages (except mortality) refer only to surviving infants.

* Previous miscarriage, stillbirth or premature birth.

$\dagger$ Breech presentation, forceps or caesarean section.

occurred within two and a half days of birth. The cumulative distribution of times of death was as follows: to 12 hours $24 \cdot 2 \%$, to 24 hours $38 \%$, to 36 hours $58 \cdot 6 \%$, to 48 hours $76 \cdot 3 \%$ and to 60 hours $86.4 \%$. In general, with the exception of severe congenital malformations, the babies dying before 24 hours tended to be smaller (average weight 1,187 g.) than those dying later than 24 hours after birth (average weight $1,506 \mathrm{~g}$.). There were several exceptions, however.

In our case material a poor prognosis was associated with the following circumstances: the second twin of premature twin births, maternal metabolic disease (diabetes, chronic renal disease), complications of birth (breech presentation, etc.), caesarean section, delay in the onset of respiration and, to a slight extent, primiparity. Toxaemia of pregnancy, which was rare, staining of amniotic fluid, and the fact that the mother was working, were not noted to be more frequent in the histories of infants who died.

As can be seen from Table 2, mortality was related both to birth weight and gestational age. These figures are coloured somewhat by the policy of admission to the department, which tends to select more on the basis of clinical condition than rigid criteria of birth weight and gestational age.

Since this study was not designed specifically to investigate the causes of prematurity or neonatal mortality, the data summarized briefly above will not be analysed in detail. We were primarily interested in preventable morbidity in premature infants, and thus babies who subsequently died were not included in groups used for the study of clinical behaviour.
Morbidity. Table 3 shows that not only mortality, but also morbidity was found to be related both to birth weight and gestational age. The incidence of respiratory and neurological abnormalities, as well as the presence of clinically apparent oedema, tended to decrease with increasing length of gestation. The group 2,000-2,500 g., 35-36 weeks gestation, is that into which the babies of diabetic and 'prediabetic' mothers often fell, i.e. babies somewhat heavier than might be expected from gestational age. Since such babies are notoriously oedematous, it is not surprising to find a relatively high incidence of clinical oedema in this group.

Fig. 1 illustrates the distribution of infants in our series with respect to birth weight and gestational age in weeks. The increasing mortality with decreasing weight and length of gestation is clear. The considerable range of weights for a given gestation is striking. Since the determination of true gestational length is a matter of controversy, and errors in our data cannot be excluded, an analysis of only two groups of infants was attempted. These were the extremes, i.e. babies smaller or larger than would be predicted from curves relating length of intrauterine life with birth weight. Group 1 comprised infants of birth weight 2,250-2,500 g., gestational age less than 35 weeks, and Group 2 of birth weight 1,500-2,000 g. with gestational ages of over 36.5 weeks. In each group one infant died: in Group 1, the infant of a diabetic mother with severe hyaline membrane disease, and in Group 2 a severely hypotrophic baby with multiple congenital malformations.

When comparing the two groups (Table 4), it is 
striking how much worse the large immature babies fared clinically, with respect to respiratory and neurological disturbances during the first few days of life. The condition at birth did not prove a particularly reliable guide to the subsequent clinical course. Maternal age did not differ significantly and both groups of mothers had, on the average, poor obstetrical histories. Mothers of Group 1 with relatively large, immature babies were more often housewives and in general shorter and heavier $(157 \mathrm{~cm} ., 63.8 \mathrm{~kg}$.) than mothers in Group 2 (162 $\mathrm{cm}$., $60.5 \mathrm{~kg}$.). The larger weight loss in Group 1 is probably attributable both to the presence of oedema, and to the lower food intake of these ill infants.

Regurgitation. For purposes of statistical evaluation, all infants followed satisfactorily for four days after birth were included in a group used for study of the interrelation of nutrition, body temperature, etc. This group included 80 ill and well infants over $1,000 \mathrm{~g}$. birth weight. Infants given chlorpromazine for whatever indication were excluded from study unless otherwise stated.

Does regurgitation represent a significant nutritional handicap during the first days of life? Recognizing that many factors influence early weight loss, e.g. food intake, stools, urine, oedema and possibly body temperature, the frequency of regurgitation and the loss of weight over the first four days were compared. The average number of times regurgitation occurred was found to be $4 \cdot 4 \pm 4 \cdot 1$, and the average weight loss $157 \cdot 5 \mathrm{~g}$. $\pm 52 \cdot 1 \mathrm{~g}$. The correlation coefficient was found to be +0.3520 , p $<0.01$. If the total fluid intake was eliminated from consideration (Fisher, 1948) the coefficient remained significant, i.e. $+0.2487, \mathrm{p}>0.02,<0.05$.

The frequency of regurgitation over the first four days was then compared to the number of stools passed over this period in an attempt to detect any any gross over- or underactivity of the intestine which might be related to regurgitation. The number of stools passed was on the average $8 \cdot 4 \pm$ $1 \cdot 3$, and it was found to bear no relation (correlation $+0.0406)$ to the frequency of vomiting recorded.

How was regurgitation related to the size and maturity of infants? The average weight of the group was $2,102 \pm 2 \cdot 4 \mathrm{~g}$. The correlation with birth weight was insignificant: -0.0349 , but was suggestive in the case of gestational maturity, i.e. $-0 \cdot 1849, \mathrm{p}>0 \cdot 05,<0 \cdot 1$. Thus less mature infants tended to vomit more in the first days of life, although, as will be seen below, this may well be an artefact due to the higher incidence of morbidity among more premature infants.

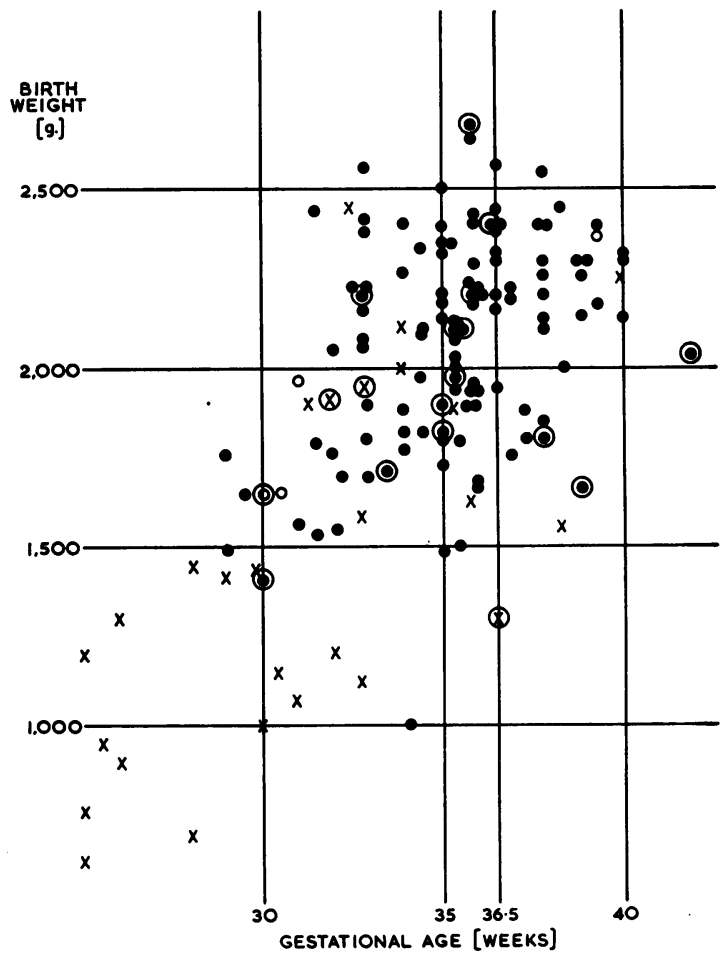

FIG. 1.-Birth weight and length of gestation.

surviving infants; $x$ infants born alive, but dying within two weeks; $\odot$ multiple birth.

Table 5 summarizes the frequency of regurgitation in infants showing respiratory or neurological abnormalities in the first four days of life, according to whether they received sedation (chlorpromazine or allobarbital), or were fed by tube. It appears that respiratory or neurological abnormality was associated with a higher incidence of regurgitation if sedation and tube feeding were not employed. In fact, this group comprised infants with relatively minor degrees of clinical disturbance, where treatment with drugs was not considered necessary and sucking ability seemed adequate. It was noteworthy that all groups of ill infants showed an unusually wide variation in frequency of regurgitation, since they included babies who vomited either a great deal or very little. Despite the small numbers involved, however, it appeared that sedation and tube feeding were of value in decreasing vomiting.

Since sedation did seem to have some effect upon regurgitation, at least in ill infants, it was decided to estimate the relation between 'restlessness' in 
NEONATAL MORBIDITY IN 'LARGE, YOUNG

\begin{tabular}{|c|c|c|c|c|c|c|c|}
\hline \multirow{2}{*}{$\begin{array}{l}\text { Number } \\
\text { Surviving } \\
\text { Infants }\end{array}$} & \multirow{2}{*}{$\begin{array}{c}\text { Gestational } \\
\text { Age } \\
\text { (weeks) }\end{array}$} & \multirow{2}{*}{$\begin{array}{l}\text { Birth } \\
\text { Weight } \\
\text { (g.) }\end{array}$} & \multirow{2}{*}{$\begin{array}{l}\text { Length } \\
\text { (cm.) }\end{array}$} & \multirow{2}{*}{$\begin{array}{l}\text { Weight } \\
\text { Loss } \\
\text { (g./4 days) }\end{array}$} & \multicolumn{2}{|c|}{ Total Intake } & \multirow{2}{*}{$\begin{array}{c}\text { Day } \\
\text { Birth Weigh } \\
\text { Attained }\end{array}$} \\
\hline & & & & & Fluid (ml.) & Calories & \\
\hline 6 & $\leqq 35$ & $2,378 \pm 52$ & $46.4 \pm 0.9$ & $\begin{array}{c}227 \pm 31 \\
(9 \cdot 5 \%)\end{array}$ & $115 \pm 27$ & $53 \pm 24$ & $18 \cdot 7 \pm 3 \cdot 9$ \\
\hline 6 & $<36.5$ & $1,790 \pm 72$ & $45 \cdot 2 \pm 1 \cdot 9$ & $\begin{array}{l}73 \pm 27 \\
(4 \cdot 1 \%)\end{array}$ & $182 \pm 10$ & $111 \pm 10$ & $10 \cdot 8 \pm 1 \cdot 9$ \\
\hline
\end{tabular}

TABLE 5

VOMITING IN ILL AND WELL PREMATURE INFANTS DURING THE FIRST FOUR DAYS OF LIFE

\begin{tabular}{|c|c|c|c|c|}
\hline Number & $\begin{array}{c}\text { Respiratory, Neurological } \\
\text { Abnormality }\end{array}$ & Sedation & Tube Feeding & $\begin{array}{l}\text { Frequency of } \\
\text { Regurgitation }\end{array}$ \\
\hline $\begin{array}{r}62 \\
9 \\
4 \\
15 \\
9 \\
20\end{array}$ & $\begin{array}{l}\text { No } \\
\text { Yes } \\
\text { Yes } \\
\text { Yes } \\
\text { Yes } \\
\text { Yes }\end{array}$ & $\begin{array}{c}\text { No } \\
\text { No } \\
\begin{array}{c}\text { Chlorpromazine } \\
\text { Allobarbital } \\
\text { Yes }\end{array}\end{array}$ & $\begin{array}{l}\text { No } \\
\text { Yes } \\
\text { Yes }\end{array}$ & $\begin{array}{l}4.24 \pm 1.29 \\
6.87 \pm 3.54 \\
5.25 \pm 2.04 \\
3.06 \pm 3.56 \\
3.00 \pm 3.46 \\
1.75 \pm 2.44\end{array}$ \\
\hline
\end{tabular}

normal infants and the frequency of vomiting. Nurses estimated restlessness or somnolence before feeds as part of their notes on behaviour. In fact, since criteria of 'restlessness' were subjective, only vigorous crying or sleep were used to divide infants into three groups: very somnolent, very restless or intermediate, and only the extreme groups were compared with respect to frequency of regurgitation.

Fourteen were 'restless' $(2 \cdot 86 \pm 2 \cdot 10)$ and 29 were somnolent $(4 \cdot 69 \pm 3 \cdot 10)$.

The difference between the two types of infants was not statistically significant, although somnolent babies tended to vomit more and had the higher proportion of severe, prolonged vomiting. It should be borne in mind, however, that the criteria of 'restlessness' were in fact signs of hunger, and vigorous babies who cried a good deal were by and large those who took feeds eagerly.

An important question to be examined was if the manner of feeding influenced regurgitation in the first days of life. It proved impossible to judge whether delaying feeding beyond the first 12 to 18 hours of life minimized vomiting, since the vast majority of infants, even ill ones, received oral food during the first day of life. It could only be said that infants who subsequently vomited frequently did so within the first 12 hours before being fed.

It was possible, however, to compare fluid intake with the frequency of regurgitation. The fluid intake over four days was inversely related to regurgitation $(-0 \cdot 2098, \mathrm{p}<0.01)$, probably because fluid intake was limited in those infants who vomited frequently. When the fluid intake for the first two days only (before this policy could have effect) was compared with the incidence of regurgitation, no significant correlation was found between fluid intake during the first two days of life and the frequency of vomiting $(-0 \cdot 1315, p>0 \cdot 1)$. The most that one can say is that the amount of fluid routinely given on our ward (average 160.2 \pm $45.8 \mathrm{ml} . / \mathrm{kg}$./four days) does not appear to have caused regurgitation.

Is there any relation between the composition of food, i.e. breast milk or 5\% glucose, and the tendency to vomit? The ratio between fluid volume and calorific value was taken as a measure of density of feeds as well as of their composition. The ml./calorie ratio for breast milk was taken as $1 \cdot 43$, and that for $5 \%$ glucose as $5 \cdot 00$. The average $\mathrm{ml}$./calorie ratio for feeds during the first four days of life was found to be $1.66 \pm 0.22$ (range 1.43 to $2 \cdot 40$ ) with smaller and ill babies tending to receive less milk and to have higher $\mathrm{ml}$./calorie ratios.

No relation was found between $\mathrm{ml}$./calorie ratios and regurgitation over the first four days in the group as a whole, or in groups of infants with respiratory or neurological abnormality, either sedated or not.

No correlation was found between caloric intake (average $98 \cdot 2 \pm 27 \cdot 4$ calorie $/ \mathrm{kg}$./four days) and the frequency of regurgitation. Caloric intake per kg. body weight was closely related to birth weight $(+0.5582, p<0.01)$ as well as gestational age 


\begin{tabular}{c|c|c|c|c|c}
\hline $\begin{array}{c}\text { Maternal } \\
\text { Age } \\
\text { (yrs) }\end{array}$ & $\begin{array}{c}\text { Mother } \\
\text { Employed }\end{array}$ & $\begin{array}{c}\text { Abnormal } \\
\text { Birth }\end{array}$ & $\begin{array}{c}\text { Caesarean } \\
\text { Section }\end{array}$ & $\begin{array}{c}\text { Delayed } \\
\text { Onset of } \\
\text { Respiration }\end{array}$ & Respiratory \\
\hline $30 \pm 6$ & 2 & 2 & 0 & 2 & Neurological \\
\hline $30 \pm 3$ & 4 & 2 & 0 & 0 & 0 \\
\hline
\end{tabular}

TABLE 6

REGURGITATION IN PREMATURE INFANTS DURING THE FIRST FOUR DAYS OF LIFE

\begin{tabular}{|c|c|c|c|c|c|c|c|c|c|}
\hline \multirow{2}{*}{$\begin{array}{l}\text { Regurgitation } \\
\text { Grades* }\end{array}$} & \multirow[t]{2}{*}{ Number } & \multicolumn{3}{|c|}{$\begin{array}{l}\text { Regurgitation Intensity } \\
(\%)\end{array}$} & \multirow{2}{*}{$\begin{array}{c}\text { 'Reluctance } \\
\text { to Feed' on } \\
\text { Day 1, } 2 \\
(\%)\end{array}$} & \multirow{2}{*}{$\begin{array}{c}\text { Vomiting } \\
\text { Within } \\
\text { 0-12 Hours } \\
(\%)\end{array}$} & \multirow{2}{*}{$\begin{array}{c}\text { 'Aspiration'† } \\
(\%)\end{array}$} & \multirow{2}{*}{$\begin{array}{c}\text { Caesarean } \\
\text { Section } \\
(\%)\end{array}$} & \multirow{2}{*}{$\begin{array}{c}\text { Abnormal } \\
\text { Birth }+ \\
(\%)\end{array}$} \\
\hline & & 1 & 2 & 3 & & & & & \\
\hline 1 & 31 & $90 \cdot 4$ & $9 \cdot 6$ & 0 & $19 \cdot 4$ & $6 \cdot 4$ & $6 \cdot 4$ & $13 \cdot 0$ & $32 \cdot 2$ \\
\hline 2 & 34 & 0 & 100 & 0 & $14 \cdot 7$ & $38 \cdot 2$ & $11 \cdot 8$ & $5 \cdot 9$ & $26 \cdot 5$ \\
\hline 3 & 41 & 0 & $24 \cdot 4$ & $75 \cdot 6$ & $29 \cdot 2$ & $51 \cdot 2$ & $29 \cdot 2$ & $7 \cdot 3$ & $24 \cdot 4$ \\
\hline
\end{tabular}

* Regurgitation grades 1 are composed of infants vomiting the least, and grades 3 of infants vomiting the most.

+ A clinical diagnosis based upon the presence of excessive oral and nasal mucus the first day of life.

$\ddagger$ Breech or forceps delivery.

$(+0 \cdot 3502, p<0 \cdot 01)$. Thus, the smaller and more immature babies tended to receive substantially fewer calories per $\mathrm{kg}$. body weight than larger infants.

Some further factors operative in the perinatal period were compared with the frequency of subsequent regurgitation, and the percentages of infants vomiting often, little or with average frequency are shown for each of these factors (Table 6). It is of some interest that the frequency and amount of regurgitation in the first four days of life were usually correlated, although, exceptionally, infants may vomit frequently in small amounts or rarely in large amounts. The presence of clinical aspiration of amniotic fluid, vomiting in the first 12 hours (before food was given), and reluctance to feed seemed reliable indications of subsequent difficulties with regurgitation. Unfortunately, the effect of gastric aspiration and washout could not be judged, since relatively few infants received such treatment and these had grossly aspirated amniotic fluid during birth.

Weight Loss. The average weight loss over the first four days of life in the group of 80 infants used for correlation studies of regurgitation was $157 \cdot 5 \pm$ $52 \cdot 1 \mathrm{~g}$., about $7 \cdot 5 \%$ of birth weight. As has been pointed out, the degree to which infants regurgitate affects weight loss significantly, and it is not surprising that caloric and fluid intake and the numbers of stools passed were not found to be significantly related to weight loss in the first days of life.

One might expect the presence of clinical oedema to be reflected in the rate of weight loss, since visible oedema must form a sizeable proportion of body weight. In fact, recorded clinical oedema was associated with an unusually large weight loss in only about one-third of cases. In the remainder, weight loss was either abnormally low with persistence of oedema, or loss was intermediate with gradual disappearance of visible oedema. It seemed that those infants who showed large weight losses with discharge of oedema within two days, in general, did better clinically. Thus, of 11 infants

TABLE 7

BODY TEMPERATURES OF II.L AND WELL PREMATURE INFANTS OF BIRTH WEIGHT 1,500-2,000 g.

\begin{tabular}{|c|c|c|c|c|}
\hline & \multirow{3}{*}{ III } & \multicolumn{3}{|c|}{ Body Temperature $\left({ }^{\circ} \mathrm{C}.\right)$} \\
\hline & & \multicolumn{2}{|c|}{ Chlorpromazine } & \multirow{2}{*}{ Total } \\
\hline & & Yes & No & \\
\hline In incubator & $\begin{array}{l}\text { Yes } \\
\text { No }\end{array}$ & $\begin{array}{l}35 \cdot 30 \text { (11) } \\
36 \cdot 01 \text { (4) }\end{array}$ & $\begin{array}{ll}36 \cdot 63 & (7) \\
36 \cdot 71 & (3)\end{array}$ & $\begin{array}{l}35 \cdot 55 \pm 0 \cdot 58 \\
36 \cdot 22 \pm 0 \cdot 42\end{array}$ \\
\hline Out of incubator & No & $36.01 \quad(2)$ & $36 \cdot 47$ (13) & $36 \cdot 41 \pm 0 \cdot 60$ \\
\hline
\end{tabular}

Figures in parentheses are numbers of infants. Differences between infants receiving chlorpromazine or not $(t=2 \cdot 63, \mathrm{p}<0 \cdot 02,>0 \cdot 01)$ and between ill and well infants in incubator $(t=2.92, \mathrm{p}<0.01)$. are significant. 
with respiratory difficulties, seven had large weight losses by the fourth day, and four of these showed marked, often dramatic, clinical improvement. Four infants retained oedema, had very small weight losses, and only one of these showed any improvement.

Fig. 2 illustrates three cases in which dramatic weight loss occurred within the first week of life. In Cases 1 and 2 large weight losses were associated with striking clinical improvement, and in Case 3, improvement occurred, although minor oedema persisted for several days longer. Of these three, only Case 1 had classical respiratory distress syn-
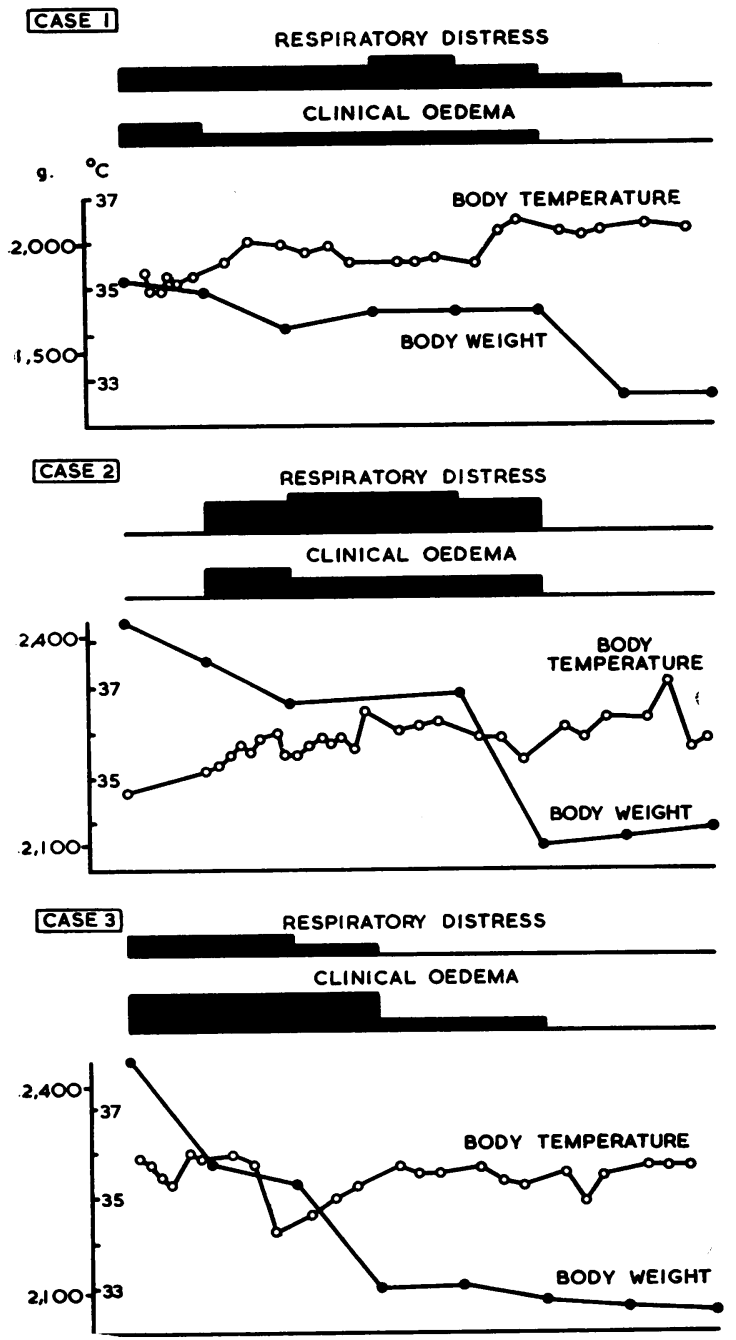

Fig. 2.-Weight loss and clinical signs in three premature infants. drome. Cases 2 and 3 showed respiratory depression, very superficial respiration with occasional apnoea, and hyperirritability. This will be the subject of a more detailed study (Cort, 1961).

Following the initial weight loss after birth, there was a varying interval during which body weight remained steady, despite increasing food intake. This phenomenon has been frequently noted in premature infants and might be termed 'plateauing'. Weight sometimes remained the same for a week or more while caloric intake might have doubled. Abnormal stools, clinical illness or infusions could not, in most cases, explain the course of weight gain. This interval, preceding steady weight gain, was most marked in small infants where it sometimes lasted one to several weeks, and least marked in mature infants where it might be absent altogether. Thus, of infants with a gestational age of 35 or less weeks, $86 \%$ showed more or less 'plateauing', average duration seven days. The comparable incidences for the gestational age groups 35-36 weeks and 37 or more weeks were $70 \%$ and $40 \%$ respectively. The average duration of the plateau in the latter groups was five and three days, respectively.

Infants who did not plateau gained sooner, while receiving relatively fewer calories. Thus, of the group of most mature infants, the $40 \%$ who showed plateauing of body weight started a steady weight gain on day nine, on the average, while receiving 113 calories $/ \mathrm{kg}$. The majority who did not plateau started gaining two and a half days earlier, while receiving an average of 82 calories $/ \mathrm{kg}$. body weight.

Temperature. Premature infants notoriously have low and unstable body temperatures. It was of some interest to study to what extent birth weight, gestational age, nursing unclothed in an incubator, and illness affected body (rectal) temperature. The group of 80 infants who did not receive chlorpromazine was used to correlate average body temperature over the first four days of life with birth weight and gestational age. When no account was taken of other factors, no significant correlation was found.

Fig. 3, however, shows the average body temperature of infants versus weight loss during the first two days of life. Those infants with respiratory or neurological abnormality are indicated, as are those receiving chlorpromazine.

Table 7 represents a further analysis of the causes of low body temperatures in ill infants. It was clear that the presence of significant illness was associated with low body temperatures in the weight 
TABLE 8

BODY TEMPERATURES IN PREMATURE INFANTS DURING THE FIRST FOUR DAYS OF LIFE (WITHOUT REGARD TO BIRTH WEIGHT OR INCUBATOR NURSING)

\begin{tabular}{|c|c|c|c|c|c|c|}
\hline \multirow{3}{*}{$\begin{array}{c}\text { Gestational } \\
\text { Age } \\
\text { (weeks) }\end{array}$} & \multirow{3}{*}{ Number } & \multicolumn{4}{|c|}{ Temperature $\left({ }^{\circ} \mathrm{C}.\right)$} & \multirow{3}{*}{$\begin{array}{c}\text { With Temperature } \\
37^{\circ} \mathrm{C} \text { or Over } \\
(\%)\end{array}$} \\
\hline & & \multicolumn{4}{|c|}{ Day } & \\
\hline & & One & Two & Three & Four & \\
\hline $\begin{array}{l}35 \\
35-36 \\
37 \text { or over }\end{array}$ & $\begin{array}{l}15 \\
24 \\
20\end{array}$ & $\begin{array}{l}36 \cdot 54(1) \\
36 \cdot 52(7) \\
36 \cdot 64(6)\end{array}$ & $\begin{array}{l}36 \cdot 63(3) \\
36 \cdot 70(7) \\
36 \cdot 70(4)\end{array}$ & $\begin{array}{l}36 \cdot 69(2) \\
36 \cdot 70(4) \\
36 \cdot 65(3)\end{array}$ & $\begin{array}{l}36 \cdot 58(2) \\
36 \cdot 70(0) \\
36 \cdot 79(4)\end{array}$ & $\begin{array}{l}53 \\
71 \\
90\end{array}$ \\
\hline
\end{tabular}

Figures in parentheses are numbers of infants with temperatures of $37^{\circ} \mathrm{C}$. or over.

group $1,500-2,000 \mathrm{~g}$. Chlorpromazine appeared to lower body temperature significantly, although the fact that infants receiving this drug tended to be the more seriously ill may mask the physiological or pharmacological significance of this finding. Being unclothed in an incubator did not seem in itself to cause a lowering of temperature, but the numbers here are small. Incubator temperatures were in general kept $1-2^{\circ} \mathrm{C}$. below rectal temperature, the principal aim being to prevent sudden or large changes in body temperature.

Low body temperatures in larger ill infants were also observed, and in all infants body temperature seemed a reliable indication of the clinical condition, often changing with surprising rapidity with improvement or worsening, i.e. in a matter of three to six hours.

Instability of body temperature was evident in both hypo and hyperpyrexia in premature infants. Normal premature infants are swaddled, and cubicles are air-conditioned to $28 \pm 2^{\circ} \mathrm{C}$., and under these conditions body temperatures over $37^{\circ} \mathrm{C}$. are not uncommon, though not sustained over an hour or so except in the presence of frank dehydration.

Table 8 shows that the frequency with which body temperatures of over $37^{\circ} \mathrm{C}$. are found is somewhat dependent upon maturity. Gross dehydration was observed by the fourth day usually in the most mature infants, and indeed the fact that 'spikes' of higher temperature were most frequent on the first and second days speaks against their being a manifestation of dehydration.

Maturity. The most reliable guide to maturity and good prognosis was found to be evidence of hunger during the first two to three days of life, as suggested by Söderling (1953). Two groups of infants, one which showed and the other which did not show eagerness to feed according to nurses' observations, were selected from among infants who were not ill. Table 9 summarizes data pertaining to these two groups.

There were no differences between the two groups with respect to the degree of regurgitation. The
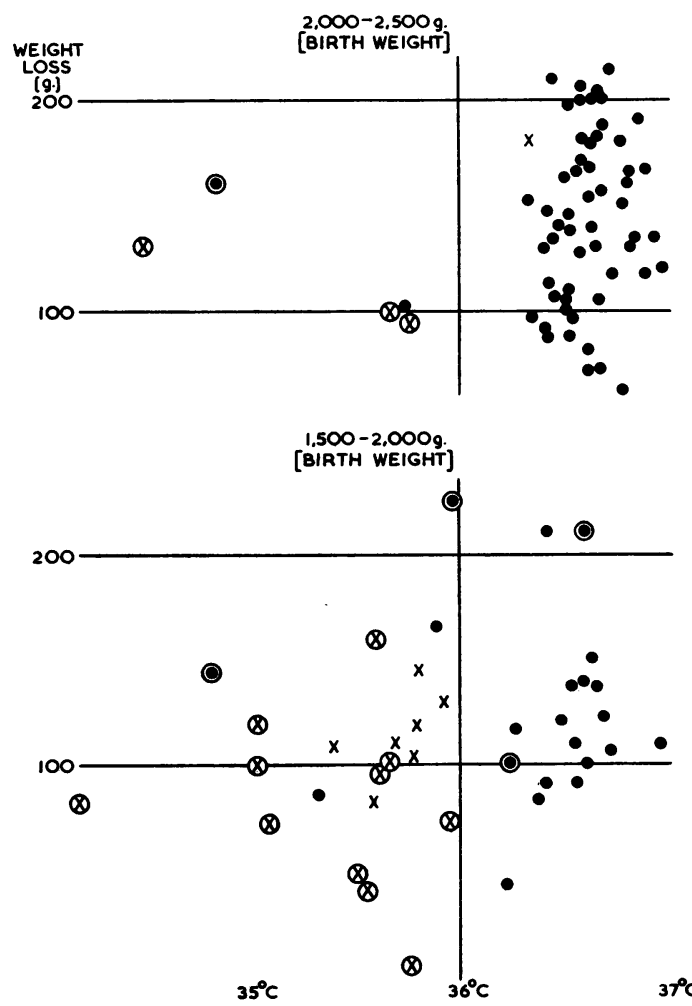

Fig. 3.-Body temperature and weight loss in well and ill premature infants: upper-infants of birth weight 2,000-2,500 g.; lower-infants of birth weight $1,500-2,000 \mathrm{~g}$.; abscissa-average body temperature (rectal) days 1 and 2; ordinate-body weight loss (g.) days 1 and 2. - well infants; $x$ ill infants; $\odot$ infants receiving chlorpromazine within six hours of birth. 
TABLE 9

SIGNIFICANCE OF EVIDENCE OF HUNGER IN FIRST FOUR DAYS OF LIFE

\begin{tabular}{|c|c|c|c|c|c|c|c|}
\hline & & Number & $\begin{array}{l}\text { Birth } \\
\text { Weight } \\
\text { (g.) }\end{array}$ & $\begin{array}{c}\text { Gestation* } \\
\text { (weeks) }\end{array}$ & $\begin{array}{c}\text { Average Body } \\
\text { Temperature } \\
\text { ( }{ }^{\circ} \text { C.) }\end{array}$ & $\begin{array}{l}\text { Weight } \\
\text { Loss } \\
\text { (g.) }\end{array}$ & $\begin{array}{c}\text { Day } \\
\text { Birth Weight } \\
\text { Attained }\end{array}$ \\
\hline $\begin{array}{l}\text { With hunger .. } \\
\text { Without hunger }\end{array}$ & $\begin{array}{l}\ldots \\
\cdots\end{array}$ & $\begin{array}{l}25 \\
23\end{array}$ & $\begin{array}{l}2,281 \pm 127 \\
2,221 \pm 120\end{array}$ & $\begin{array}{l}36 \cdot 8 \pm 1 \cdot 9 \\
35 \cdot 6 \pm 4 \cdot 5\end{array}$ & $\begin{array}{l}36.71 \pm 0.09 \\
36.66 \pm 0.66\end{array}$ & $\begin{array}{r}-151 \pm 31 \\
-152 \pm 34\end{array}$ & $\begin{array}{l}12.4 \pm 2.4 \\
14.4 \pm 3.9\end{array}$ \\
\hline
\end{tabular}

* Difference in gestational age is $1 \cdot 2$ weeks $(t=1 \cdot 71, \mathrm{p}>0 \cdot 05,<0 \cdot 10)$.

longer period required for reluctant feeders to attain birth weight was a reflection of their slightly lower food intake, and differences in rate of gain between the two groups disappeared after the first fortnight.

\section{Discussion}

Although a relatively small number of premature infants was included in this case material, the dependence of mortality upon birth weight and gestational age was clear, and was in agreement with previous reports in the literature (Steiner and Pomerance, 1950). Neonatal morbidity was also found to be correlated both with body size and length of gestation. The striking difference in morbidity between large immature infants and small more mature ones confirmed clinical experience. It has been pointed out that 'small, old' infants gain weight postnatally at the most rapid rate (Kunnas, 1960), and that the large premature infants of diabetic mothers behave metabolically in a manner consistent with their gestational age (Cook, O'Brien, Hansen, Beem and Smith, 1960). Unfortunately, sufficient data were not available on the mothers of our large immature babies to establish a diagnosis of prediabetes, but in six out of seven cases frank diabetes mellitus was not present.

The policy of early feeding of premature infants has been in force in this department for a number of years. The reasons for its adoption were in general two: theoretical agreement with the opinion that premature infants, with small energy stores, are probably in greater need of early nutrition than full-term babies (Ford, 1949), and practical experience that provocation of vomiting and aspiration by feeding small and ill infants has not presented a real problem. The data presented here do not contribute one way or the other to the controversy on the advisability of early feeding of premature infants (Yllpö, 1954-55; Smith, 1957). The most that can be concluded is that babies who are going to vomit a good deal start to do so before any food is given, and that the physical volume or nature of food given does not seem to influence the amount of regurgitation.
The data also give some indication of how to minimize vomiting in infants at risk, i.e. more immature babies, particularly those who have minor degrees of respiratory or neurological abnormality or who froth mucus or vomit in the early hours after birth. Prophylactic measures must be instituted early; in our experience, once severe vomiting is established, it is difficult to halt it.

Sedation and tube-feeding seemed the most effective prophylactic measures, although we were unable to evaluate gastric washout and gastric drip feeding. In addition, Holmdahl (1955) reported that intragastric drip feeding halved the incidence of vomiting in premature infants, although it was without effect on the occurrence of cyanotic attacks.

Our clinical impression is that milk feeds particularly seem to precipitate apnoea in ill infants. It is difficult to believe that the small amounts of fluid involved could exert sufficient pressure per se on vital organs to explain this. It may be that sufficient blood is diverted to the gastro-intestinal tract during digestion to embarrass the cardiovascular system of small or ill infants.

No specific anti-emetic effect of chlorpromazine, aside from its sedative action, was evident in these data. The value of this drug in sedating ill premature infants also seems to be a non-specific one (Znamenáček and Melichar, 1956). The lack of specific drug anti-emesis is perhaps not surprising in view of the findings of Törnwall, Lind, Peltonen and Wegelius (1958) that regurgitation in newborn infants does not involve antiperistalsis.

Postnatal weight loss in this group of premature infants was found to be very variable, although clearly related to the amount of vomiting during the first four days of life. This may represent the effect of vomiting on net food intake, in addition to losses of fluids and salts in vomitus over and above food given. In balance studies, these losses are occasionally found to be as high as urinary losses (Cort, 1961).

The presence of clinical oedema was not invariably associated with unusually large weight losses within the first few days of life. In balance studies it has also been found that diuresis within two days of 
birth is a common phenomenon both in normal and ill premature infants (Cort, 1961), although, as in the cases presented here, it may be delayed for up to a week after birth.

A delay in the onset of steady weight gain postnatally is common in premature infants. Metabolic studies designed to elucidate the factors involved in this phenomenon of 'plateauing' would be of considerable value. From the study reported here it was only possible to state that more mature infants seemed able to gain weight sooner after birth, and on relatively fewer calories, than more immature infants.

The association of low body temperatures with illness in premature infants could partially be accounted for by sedation, but it has been our experience that body temperature is a sensitive indicator of the general clinical condition. This may well be related to hypoxia (McCance, 1959; Karlberg, 1960). Body temperatures of over $37^{\circ} \mathrm{C}$. were not uncommon in our group of infants, as also appears from the data reported by Silverman, Fertig and Berger (1958). Spiking of body temperature up to $38^{\circ} \mathrm{C}$. was not clinically associated with dehydration in most cases, and may well be related to the presence of vasoconstriction as reported by Brück, Brück and Lemtis (1958) in newborn infants.

The finding that eagerness to feed or hunger was the most reliable reflection of gestational maturity confirms the suggestion of Söderling (1953). The converse did not seem true; occasionally babies who subsequently fed ravenously showed reluctance to feed on the first day of life.

\section{Summary}

A study of 155 'premature' infants has been carried out, with special reference to clinical behaviour in the first four days of life. The purpose was to gain information concerning morbidity in the early neonatal period, and in particular the causes and significance of regurgitation during this period. The following conclusions were made:

In agreement with general experience, the greatest mortality took place before the third day of life. Mortality and morbidity were found to be related both to birth weight and gestational age.

Infants somewhat larger than would be predicted from the length of gestation were found to have a high morbidity rate. Relatively mature, undersize babies tended to be lively and healthy.

Regurgitation significantly influenced weight loss in the neonatal period. It is more common in immature infants, probably because of the higher rate of illness among such infants. Abnormal regurgitation was usually manifest within 12 hours after birth and before feeding, and was not found to be related to the amount or type of feeding given.

It is suggested that sedation, tube feeding and, possibly, gastric aspiration are of value in minimizing regurgitation. These measures should be instituted early and prophylactically in infants who show clinical evidence of 'aspiration' during birth, those who vomit within a few hours of birth, and those with minor degrees of neurological or respiratory difficulty.

Weight loss during the first four days of life in premature infants is variable. The presence of clinical oedema is not invariably associated with unusually large weight losses. It is suggested, and some evidence is presented, that the occurrence of large weight losses suddenly after birth represents discharge of oedema, and is a phenomenon of recovery in ill infants.

Attention is called to the delay in the onset of steady weight gain which appears to be related to gestational maturity.

The presence of respiratory or neurological illness was found to be associated with a low body temperature, only partially attributable to treatment with chlorpromazine. Under the conditions of routine care employed, moderate hyperpyrexia without clinical dehydration was commonly found in the first days of life.

The most reliable indication of gestational maturity during the first days of life was found to be evidence of hunger.

The author is deeply indebted to the nursing staff of the premature department, Institute for the Care of Mother and Child, for their co-operation in this study. In particular Sister M. Krejčová gave invaluable assistance.

REFERENCES

Brück, K., Brück, M. and Lemtis, H. (1958). Thermoregulatorische Veränderungen des Energiestoffwechsels bei reifen Neugeborenen. Veränderungen des Energiestoffwech
Pflüg. Arch. ges. Physiol., 267, 382.

Cook, C. D., O'Brien, D., Hansen, J. D. L., Beem, M. and Smith, C. A. (1960). Water and electrolyte economy in newborn infants of diabetic mothers. Acta paediat. (Uppsala), 49, 121.

Cort, R. L. (1961). ibid. In the press.

Fisher, R. A. (1948). Statistical Methods for Research Workers, 10th ed. Oliver and Boyd, Edinburgh.

Ford, F. J. (1949). Feeding of premature babies. Lancet, 1, 987.

Holmdahl, K. (1952). The programme for premature infants in Gothenburg, Sweden. The principles of treatment and the Gothenburg, Sweden. The principles of treatm
results attained. Acta paediat. (Uppsala), 41, 1 .

(1955). Milk drip via an indwelling naso-gastric rubber tube for feeding premature infants. ibid., 44, 330 .

Karlberg, P. (1960). Physiological aspects of temperature and oxygen effects on newborn infants. ibid., 49 (Suppl. 122), 29.

Kunnas, M. (1960). Gestation age and growth of premature infant. Ann. Paediat. Fenn., 6, 103. 
McCance, R. A. (1959). The maintenance of stability in the newly born. Arch. Dis. Childh., 34, 361, 459.

Silverman, W. A., Fertig, J. W. and Berger, A. P. (1958). The influence of the thermal environment upon the survival of newly born premature infants. Pediatrics, 22, 876.

Smith, C. A. (1957). Reasons for delaying the feeding of premature infants. Ann. Paediat. Fenn., 3, 261.

Söderling, B. (1953). Pseudoprematurity. Acta paediat. (Uppsala), 42, 520 .
Steiner, M. and Pomerance, W. (1950). Studies on prematurity. II. Influence of fetal maturity on fatality rate. Pediatrics, 6,872 .

Törnwall, L., Lind, J., Peltonen, T. and Wegelius, C. (1958). The gastro-intestinal tract of the newborn. I. Cineradiographic findings. Ann. Paediat. Fenn., 4, 209.

Yllpö, A. (1954-55). Premature children-should they fast or be fed in the first days of life? ibid., 1, 99.

Znamenáček, K. and Melichar, V. (1956). Ošetřování nezralých novorozencú v útlumu. Čsl. Pediat., 11, 15. 